\title{
The Impact of Molecular Genetic in Acute Myeloid Leukemias
}

Patriarca A*, Salutari P and Di Zacomo S

Department of Hematology, Ospedale Civile dello "Spirito Santo", Pescara, Italy

"Corresponding author: Andrea Patriarca, Department of Hematology, "Spirito Santo" Hospital, 65124, Pescara, Italy, Tel: +39-085/4252810; Fax: +39-085/4252857; E-mail: andreapatriarca80@gmail.com

Received date: Jan 07, 2015, Accepted date: Feb 04, 2015, Publication date: Feb 10, 2015

Copyright: @ 2015 Patriarca A, et al. This is an open-access article distributed under the terms of the Creative Commons Attribution License, which permits unrestricted use, distribution, and reproduction in any medium, provided the original author and source are credited.

\begin{abstract}
The discovery and application of advanced molecular techniques, such as gene and microRNA expression profiling, whole genome and exome sequencing and methylation assays, allowed for the identification of recurrent molecular abnormalities in acute myeloid leukemia (AML) that have revolutionized our understanding of the genetic landscape of the disease. Moreover, these modalities have emerged as valuable tools that permit a more comprehensive and detailed molecular characterization of AML, helping in the prediction of prognosis, particularly within the context of cytogenetically normal AML (CN-AML). This review will discuss the major techniques and platforms that have been used to identify novel recurrent gene mutations in AML and briefly describe how these discoveries have impacted on outcome prediction.
\end{abstract}

Keywords: AML; Molecular biology

\section{Introduction}

Acute Myeloid Leukemias (AML) is a clonal hematopoietic disorder arising from the acquisition of genetic and epigenetic alterations, leading to a premature arrest of the normal differentiation of stem cells and to the accumulation of immature neoplastic cells in the blood and bone marrow. According to Bryd et al, almost $55 \%$ of newly diagnosed adult patients harbor non-random chromosomal abnormalities (e.g., deletions, translocations), which have long been recognized as the genetic events that cause and promote this disease [1].

Moreover in 1990s, the karyotypic evaluation at diagnosis emerged as the most powerful tool in defying the prognosis and the response to treatment [2] (Figure 1).

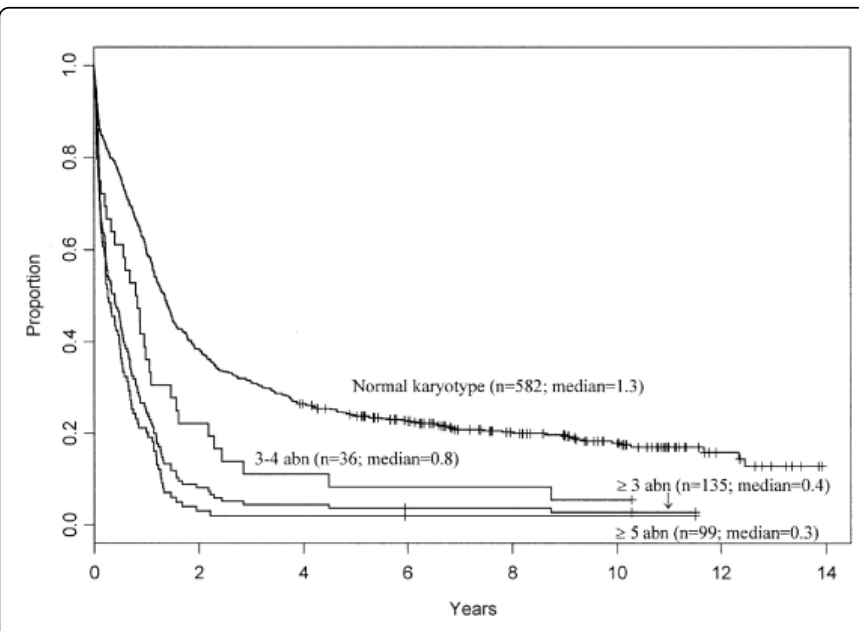

Figure 1: Survival curve after chemotherapy according to karyotype (reproduced from Byrd et al. Blood 2002 [1]).
However with the conventional karyotyping almost $50 \%$ of the patients were classified as $\mathrm{CN}$-AML and displayed an heterogeneous outcome [3,4]. Over the past two decades, advances in molecular diagnostics has improved our knowledge of AML biology and has contributed remarkably to refining overall prognosis, particularly in the subset of CN-AML [5]. In the same way, gene and microRNA expression profiling discovered the deepest perturbation following the acquisition of a specific mutation, suggesting new targets for treatment and adding further prognostic information [6].

Lastly whole genome sequencing of AML patients uncovered new mutations in AML that have also an impact on prognosis. The integration of the data is critical to guide future therapeutic strategies. Herein we will describe molecular techniques and platforms that have been used to discover novel mutations and gene expression signatures in AML and how these discoveries have refined prognosis in AML.

\section{Molecular Diagnostic in AML}

\section{Gene mRNA expression microarrays}

The genes' mRNA expression levels were determined mainly using single real time PCR assays. While this is still of paramount importance in the measurement of single gene expression, the development of microarray platforms allowed the simultaneous measurement of multiple genes' expression in a one step-assay. With this approach we gained knowledge about unique gene expression signatures associated with defined cytogenetics and molecular subgroups of AML $[7,8]$. The use of gene expression profiling (GEP) has also identified novel sub-types of disease, particularly in CN-AML $[9,10]$ and has been helpful in identifying potential targets of therapy $[11,12]$. GEP is highly accurate in predicting cytogenetically favorable AML subtypes, such as core-binding factor (CBF-AML) and acute promyelocytic leukemias. However, it is less accurate in predicting intermediate and high risk cytogenetic subtypes (such as monosomy 7 and 11q23) [13] with the exception of FLT3-ITD, where gene expression signatures using mRNA microarrays were found to outperform FLT3-ITD mutation status in predicting disease outcome, 
Citation: Patriarca A, Salutari P, Di Zacomo S (2015) The Impact of Molecular Genetic in Acute Myeloid Leukemias. J Blood Disorders Transf 6:

Page 2 of 12

thereby supporting the use of GEP in these cases [14-16]. Moreover in older adults, GEP studies revealed signatures that were unique and distinct from those of younger patients and suggestive of a different biology [17]. Recently, the multi-national Microarray Innovations in Leukemia (MILe) study, in which whole GEPs were studied in 11 laboratories on 3.334 patients, demonstrated the high level of accuracy in classifying subtypes of AML and argues for the use of this modality on a broad scale [18]. However as reported by Mills et al., although the
DC model proved to be very accurate in the classification of leukemia, it failed in discriminating between AML and Myelodysplastic Syndromes in almost $50 \%$ of MDS samples[19]. Moreover the same group [20] reported a significant difference in AML progression among MDS discordant cases depending on the GEP stratification into 3 different categories (AML-like, none of the targets and MDS like) (Figure 2).

A

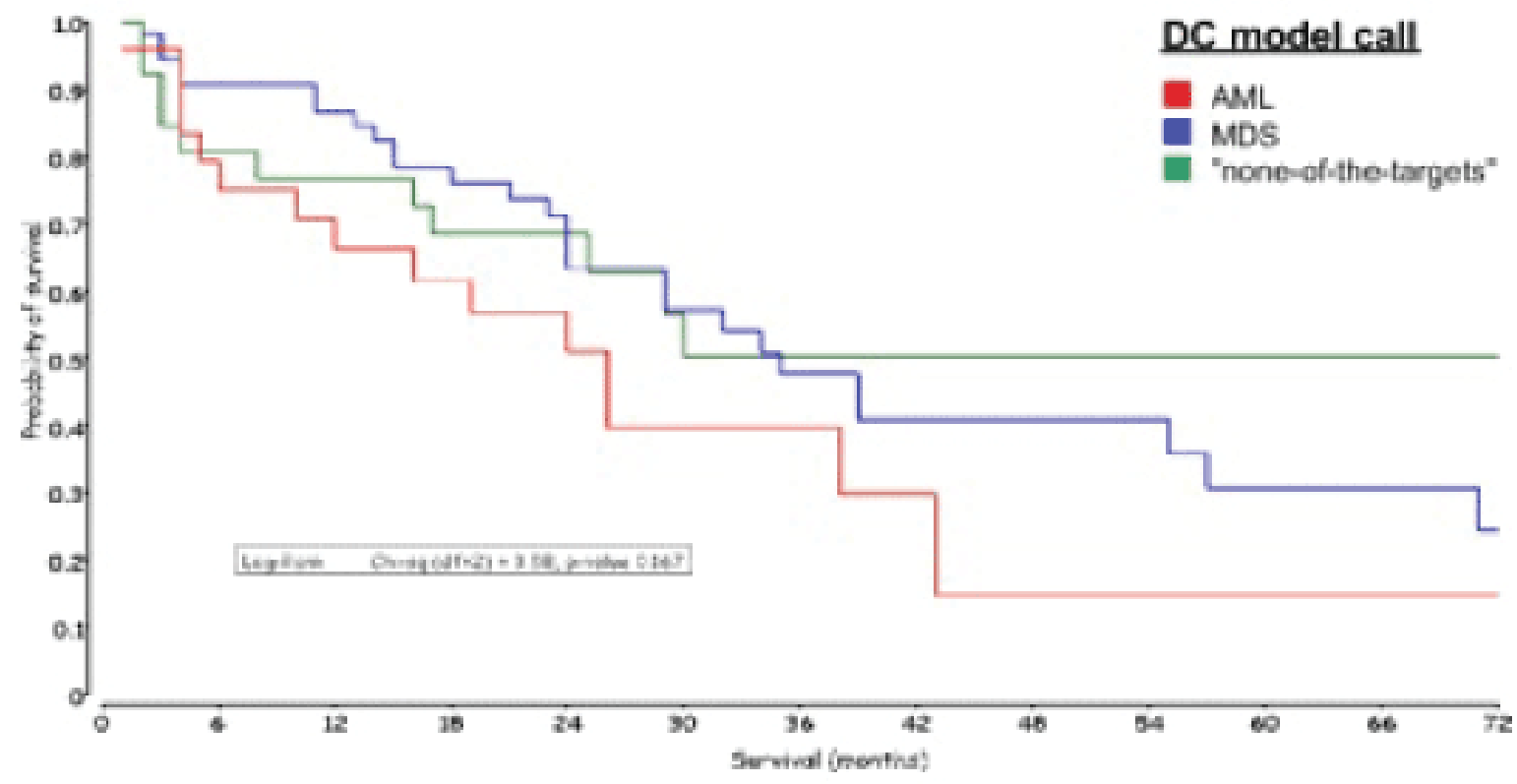

B

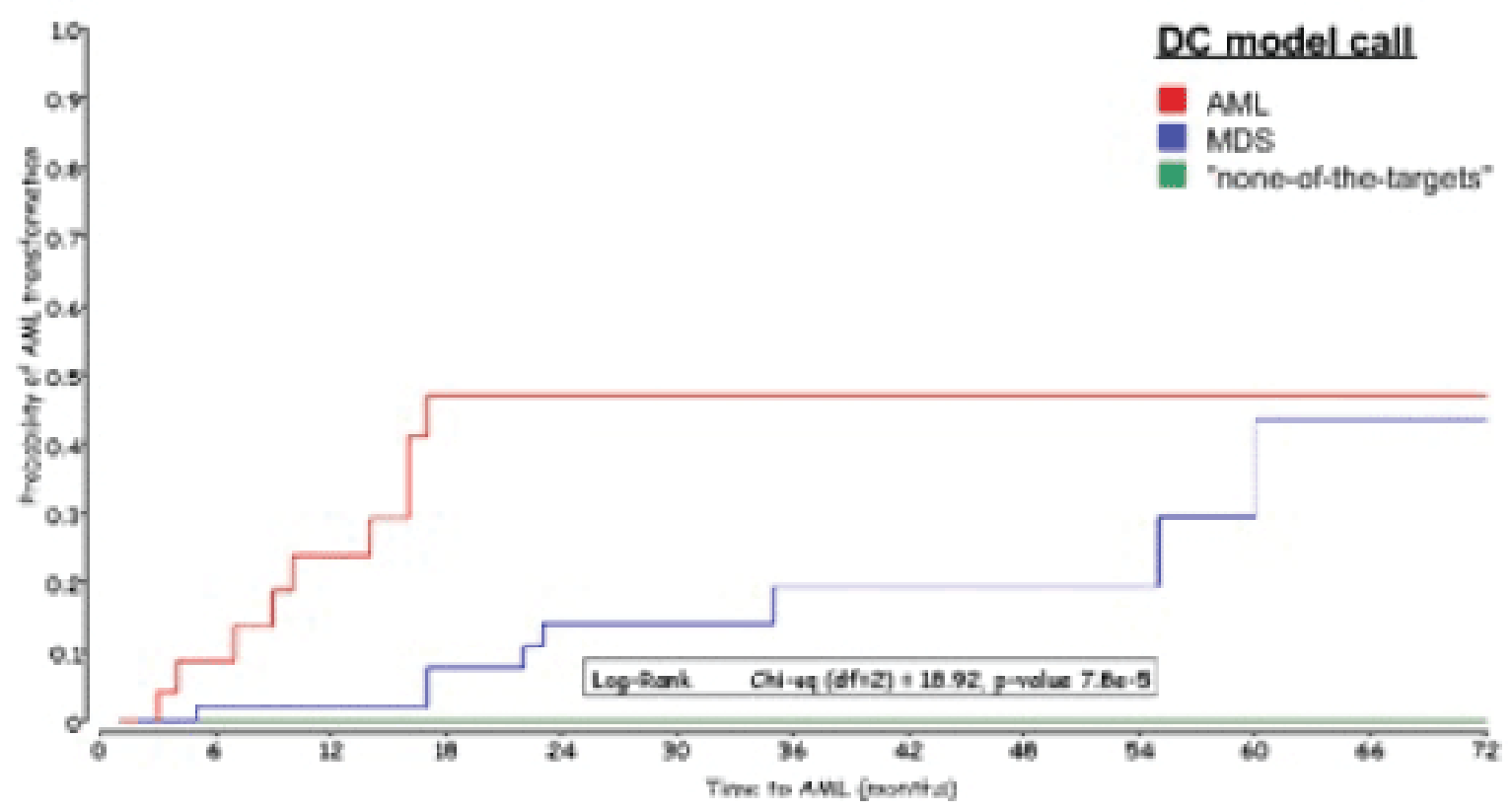

Figure 2: AML Progression according to GEP in discordant cases of MDS (reproduced from Mills et al. Blood 2009 [16]). 
Citation: Patriarca A, Salutari P, Di Zacomo S (2015) The Impact of Molecular Genetic in Acute Myeloid Leukemias. J Blood Disorders Transf 6:

Page 3 of 12

\section{MicroRNA expression microarrays}

The micro-RNAs are small (19-25 nucleotides long) RNAs, acting as regulators of genes' RNA translation by binding them. An aberrant expression patter has been reported in different cancers and in AML. As shown in Table 1 in the last years there have been an ever growing burden of report regarding micro-RNAs' expression in AML. These experiences had two major merits: on one hand they were able to add new insights in AML biology, both in molecular defined and $\mathrm{CN}$ AML; on the other hand they gave new valuable prognostic markers for refining the prognosis of $\mathrm{CN}-\mathrm{AML}$ and maybe in the future new targets for treatment [21-33]. Early studies reported a specific abnormal expression signatures associated with specific cytogenetic abnormalities and molecular aberrations such asFLT3-ITD, NPM1 and CEBPA mutations $[34,35]$. A landmark study in which microRNA expression profiles were obtained from 64 patients with CN-AML and high-risk molecular features (FLT3-ITD mutation, NPM1 WT) identified 12 miRNA probes, five of which were members of the miR-181 family, whose expression levels were inversely associated with event free survival (EFS) [36]. Similarly other groups found a significant correlation between hyper-expression of other miRs and a worse prognosis (miR199a [37], miR-126 [38], miR-155 [39]). Over-all these observations were the premise for the application of miRNA expression profiling at diagnosis. With this technique, Diaz et al. were able to confirm the prognostic impact of four miRNAs (miR-135a, miR-49-3p, miR-196b and miR-644) in a group of 238 patients with intermediate risk cytogenetic AML, arguing for use of this miRNA array at diagnosis in CN-AML [40]. However there is a general lack of consistency among the signatures associated with prognosis obtained from the different groups, making difficult to draw a firm conclusion and arguing the need for an extensive validation and standardization of the technique before the use in the clinical setting.

\begin{tabular}{|c|c|c|c|}
\hline $\begin{array}{l}\text { Genetic/molecular } \\
\text { subtype }\end{array}$ & Upregulated & Dowregulated & Study \\
\hline \multirow[t]{3}{*}{$\mathrm{t}(15 ; 17)$} & $\begin{array}{l}\text { miR-193b/379/382/4855p/134/376a/2995p/452/127/224/432/370/100/323/125b/ } \\
\text { 154/424/181a,b,d }\end{array}$ & miR-96a,b/151/10b/let-7c & [17] \\
\hline & miR-127/154/154*/299/323/368/370 & $\begin{array}{l}\operatorname{miR}-173 p / 185 / 187 / 194 / 200 a, b, c / \\
330 / 339\end{array}$ & [18] \\
\hline & miR-181a,b,c,d/224/368/382/424/100/125b - & $\begin{array}{l}\operatorname{miR}-126 / 126^{*} / 150 / 17-5 p / 20 a / \\
422 b / 10 a / 124^{\circ}\end{array}$ & [18] \\
\hline$t(8 ; 21)$ & $\operatorname{miR}-126^{*}$ & $\begin{array}{l}\text { let-7b,c/miR-148a/125b/99a/133a,b/ } \\
\text { 9/10a, b/ 196a,b/133a }\end{array}$ & [17] \\
\hline \multirow[t]{2}{*}{$\operatorname{inv}(16)$} & miR-424/199b/365/335/511 & miR-10a,b/196a,b/127/192/let-7b,c & [17] \\
\hline & miR-99a/100/224 & & [18] \\
\hline \multirow[t]{2}{*}{ 11q23 } & miR-326/219/194/301/324/339/99b/328 & $\begin{array}{l}\mathrm{miR}-34 \mathrm{~b} / 15 \mathrm{a} / 29 \mathrm{a} / 29 \mathrm{c} / 372 / 30 \mathrm{a} / 29 \mathrm{~b} / \\
30 \mathrm{e} / 196 \mathrm{a} / 102 / 331 / 299 / 193 / \text { let-7f }\end{array}$ & [7] \\
\hline & miR-196b/17-3p, 5p/18\%/19a, b/20\%/92/93/10a,b/124a & $\begin{array}{l}\mathrm{miR}-126 / 126^{*} / 130 \mathrm{a} / 146 \mathrm{a} / 181 \mathrm{a}, \mathrm{b}, \mathrm{c}, \mathrm{d} / \\
224 / 368 / 382 / 424\end{array}$ & [19] \\
\hline+8 & $\mathrm{miR}-124 \mathrm{a} / 30 \mathrm{~d} / 337 / 184 / 302 \mathrm{~b} / 105 / \mathrm{let} 7 \mathrm{~d} / 153 / 215 / 1 / 194$ & & [7] \\
\hline \multicolumn{4}{|c|}{ Cytogenetically normal acute myeloid leukemia } \\
\hline FLT3-ITD mutated & $\operatorname{miR}-155 / 10 b / 511 / 135 a$ & $\begin{array}{l}\operatorname{miR}-143 / 338 / 30 a-3 p / 182 / 145 / 130 a \quad / \\
214 / 203\end{array}$ & [17] \\
\hline \multirow[t]{2}{*}{ NPM1 mutated } & miR-10a,b/100/let-7a-3/21/16a,b/29a,b,c/16-1/17-92 & $\begin{array}{l}\operatorname{miR}-192 / 299 / 128 \mathrm{a} / 198 / 429 / 326 / \\
204 / 127 / 299-5 \mathrm{p} / 193 \mathrm{~b}\end{array}$ & [20] \\
\hline & miR-10a,b/196a,b/135a/let-7b & $\begin{array}{l}\operatorname{miR}-320 / 335 / 130 a / 126^{*} / 424 / 365 \\
450 / 127 / 299-5 p / 193 b\end{array}$ & [17] \\
\hline \multirow[t]{2}{*}{ CEBPA mutated } & $\mathrm{miR}-335 / 181 a$ & $\begin{array}{l}\operatorname{miR}-196 a, b / 149 / 9 / 21 / 130 b / \\
\text { let-7b/99b/148 }\end{array}$ & [17] \\
\hline & $\mathrm{miR}-128 / 181 \mathrm{a}, \mathrm{b}, \mathrm{c}, \mathrm{d} / 192 / 219-1-3 \mathrm{p} / 224 / 335 / 340$ & miR-34a/194 & [21] \\
\hline RUNX1 mutated & miR-211/220/595 & miR-223/99a/100/let7a,f & [22] \\
\hline ASXL1 mutated & None & None & [23] \\
\hline DNMT3A mutated & $\operatorname{miR}-10 a^{*} / 659 / 147 / 361-3 p$ & $\begin{array}{l}\mathrm{miR}-30 \mathrm{c}-1 * / 181 \mathrm{c} / \\
504 / 365-2 / 410 / 626 / 640\end{array}$ & [24] \\
\hline IDH2 R172 mutated & miR-1/133a/125b/125a-5p/421/374a/361-5p/26a/30d & $\begin{array}{l}\mathrm{miR}-7 / 345 / 129-5 p / 632 / 615-5 \mathrm{p} / \\
1301 / 639 / 548 \mathrm{~b} / 520 \mathrm{a}-3 \mathrm{p} / 526 \mathrm{a} / 194-1\end{array}$ & [25] \\
\hline
\end{tabular}




\begin{tabular}{|c|c|c|c|}
\hline TET2 mutated & miR-148a, 148b, 24, 640, 107 & $\mathrm{miR}-135 \mathrm{a} / 186$ & [26] \\
\hline Low MN1 expression & $\mathrm{miR}-30 \mathrm{~b} / 126 / 126^{*} / 30 \mathrm{a} / 30 \mathrm{~b} / 146 \mathrm{a} / 146 / 199 \mathrm{a} / 363$ & $\begin{array}{l}\text { let-7b/miR-10a/10a*/10b/449a/ } \\
550^{\star} / 766\end{array}$ & [27] \\
\hline $\begin{array}{l}\text { Low } \\
\text { expression }\end{array}$ & $\mathrm{miR}-222 / 130 \mathrm{a} / 130 \mathrm{~b} / 126 / 126^{\star} / 380 / 26 a / 26 \mathrm{~b}$ & $\begin{array}{l}\operatorname{miR}-9 / 9^{*} / 10 b / 10 b^{*} / 105 / 99 / 100 / l e t-7 b \\
\text { miR-10a, 10a* }\end{array}$ & [28] \\
\hline $\begin{array}{ll}\text { Low } & E R G \\
\text { expression } & \end{array}$ & $\operatorname{miR}-208 a / 144 * / 612 / 107 / 148 a$ & $\begin{array}{l}\operatorname{miR}-106 a / 147 b / 495 / 302 d / 26 a-1 * / \\
515-5 p\end{array}$ & [28] \\
\hline
\end{tabular}

Table 1: Characteristic microRNA expression signatures in different adult acute myeloid leukemia subtypes.

\section{Single nucleotide polymorphism array}

Single nucleotide polymorphism (SNP) array is a novel tool with superior resolution to detect slight variation between human genomes. This platform is very similar to a microarray platform and contains immobilized nucleic acid sequences of target, one or more labeled allele-specific oligonucleotide probes and a detection system that measures the hybridization signal. The first problem to face with such a sensible assay is the differentiation between cancer related microaberrations and germ-line derived polymorphisms. It's possible to overtake this limitation by using a second sample form a normal tissue (usually the buccal swab or a skin biopsy) as comparison [41,42]. Two recent studies of pediatric and adult AML have underscored the value of paired samples in SNP array analysis. Walter et al. [43] analyzed 86 adult AML cases using ultra-high resolution Affymetrix 6.0 SNP arrays with paired normal DNA in all cases, whereas Radtke et al. [44] studied 111 pediatric AML cases with high-resolution SNP arrays (combination of $100 \mathrm{~K}$ and $500 \mathrm{~K}$ arrays) using paired samples for 65 patients and higher stringency criteria to define abnormalities for the remaining 46 patients. The studies identified only 12 or 18 regions with significantly recurrent chromosome number abnormalities (CNAs), respectively, and an average of $2.3 \mathrm{CNAs} / \mathrm{AML}$ genome $[45,46]$. Thus, given the low frequency of recurring CNAs in AML compared with other cancers, it becomes critically important to discriminate between true acquired CNAs and inherited chromosome number variations (CNVs). However, even with ultra-high resolution arrays, and the analysis of paired normal DNA, which is needed to identify true CNAs and to eliminate confounding CNVs from the analysis, it can still be challenging to identify small CNAs $(<1 \mathrm{Mb})$ with certainty, as indicated by a low rate of validation by additional criteria and experimental analysis [37]. Both of these studies of AML reported a low frequency of CNAs, $8 \%$ and $13 \%$, in contrast to a frequency of $17 \%$ reported in a study without paired analysis [39]. Indeed, these lower frequencies are in accord with other studies on MDS, in which copy neutral loss of heterozygosity (CNLOH) was found in $12 \%$ of the cases [40]. From a practical point of view, notwithstanding the technical problems, it seems that a wide application of SNP-array in clinical practice will accomplish the goal to implement the prognostic classification of AML, allowing for a better planning of treatment in selected patients [41,42].

\section{Whole genome sequencing}

The sequencing of the entire human genome was first accomplished in 2000, mainly through the use of shotgun sequencing technology [43]. Over the past several years, the development of modern techniques such as the use of nanopore, fluoropore and pyrosequencing have made it possible to perform whole gene sequencing in a patient sample within a reasonable cost and timeframe
[44]. This progress has open a new era in genomics and now we are able to sequence, fully, the whole genome of cancer patients. It is also possible to sequence selected areas of the genome. For example, exome sequencing is a technique in which only the coding regions of the genome are sequenced [45], allowing for selective capture of the genomic regions of interest from a DNA sample prior to sequencing. It is also possible to select small RNAs using size selection, or similar capture strategies as described above, to perform comprehensive small RNA profiling in patient samples [46]. Another popular technique is the whole transcriptome sequencing or RNA-Seq, where all RNA species, including total RNA and small RNA, are sequenced [47]. This technique provides unparalleled information about alternative gene spliced transcripts, post-transcriptional changes, gene fusion, mutations/SNPs and changes in gene expression. RNA-seq also avoids several biases associated with microarray hybridization-based platforms. The limitations include reliance upon existing knowledge of genomic sequences, high background levels owing to crosshybridization, a limited dynamic range of detection (background and saturation of signals) and the necessity of complicated normalization methods to compare expression levels across different experiments [48].

In 2008, whole genome sequencing of an AML patient's genome, and its matched normal counterpart obtained from the same patient's skin, was reported in a seminal paper by Ley et al. [49]. The authors discovered ten genes with acquired mutations, whose eight were new mutations present in virtually all blasts at presentation and relapse [49]. In a second manuscript, Mardis and colleagues, using the same approach, identified 12 genes, ten of which had not been previously reported to be perturbed in AML, as primarily involved in disease pathogenesis [50]. In another recently published study, whole genome sequencing of $\mathrm{CN}$-AML genomes were compared to those from patients with a known driver mutation (PML-RARA) and hematopoietic stem cells from healthy volunteers in order to provide insight regarding clonal evolution in AML[51]. This report showed that the majority of somatic mutations in AML genomes occur randomly in hematopoietic stem cells prior to acquisition of driver mutations, and that, often, only one or two cooperating mutations are capable of producing malignant clones. The Cancer Genome Atlas Network recently used an integrative approach with either whole genome or whole exome sequencing in combination with RNA or microRNA sequencing and with DNA methylation studies in 200 patients with de novo AML in order to provide the most complete view of genetic alterations in AML [52]. In this report, AML genomes were shown to contain an average of only 13 gene mutations, which is relatively lower than the number of mutations observed in other malignancies. Additionally, AML genomes generally did not display evidence of genomic instability and several mutations were found to 
Page 5 of 12

exist in mutual exclusivity of others, thereby providing important insights regarding disease pathobiology. However, almost all AML samples were found to have at least one driver mutation involving genes known to be implicated in various AML pathogenesis mechanisms. The data obtained from this analysis have been used to generate widely available databases for future AML studies (Figure 3).

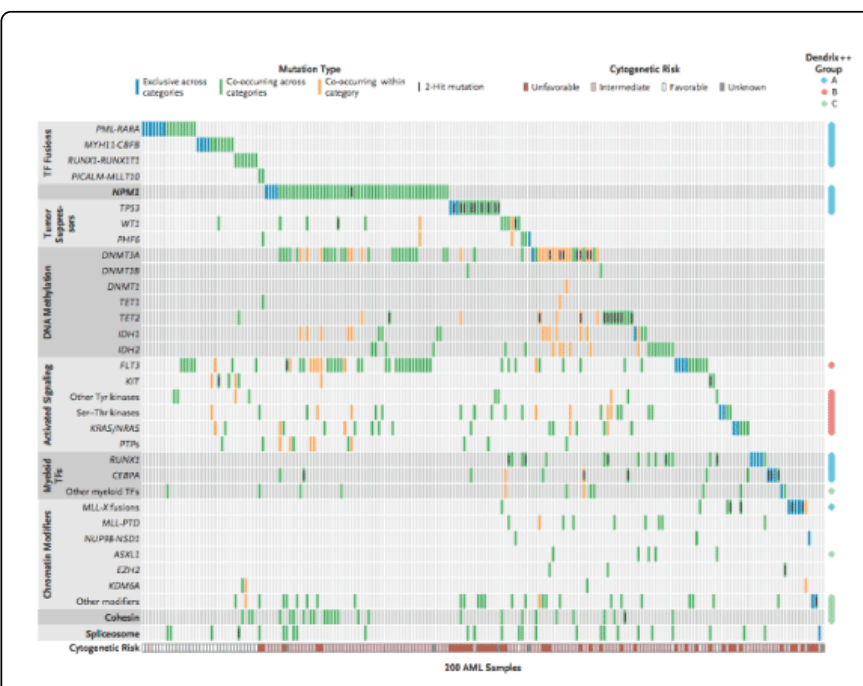

Figure 3: Organization of Mutations into Categories of Related Genes: Almost all the sample displayed one mutation in one of the listed genes or sets. Blue boxes indicate mutations that are exclusive across all categories; green boxes, mutations that co-occur in the same sample across different categories; and orange boxes, mutations that co-occur in the same sample in the same category. Computational analysis identified three significant, mutually exclusive groups of genes, annotated on the right as groups $\mathrm{A}, \mathrm{B}$, and $\mathrm{C}$. The cytogenetic risk for each patient is shown at the bottom of the chart (reproduced from Cancer Genome Atlas Research NEJM 2009 [52]).

\section{Epigenetic modifications: DNA methylation}

Hypermethylation of $\mathrm{CpG}$ islands in close proximity of promoter regions of tumor suppressor genes, leading to functional inactivation and gene silencing, has been shown to be an important and highly common mechanism in the pathogenesis of AML (reviewed in Ref. [53] and in Ref. [54]). As such, DNA methylation studies have been shown to provide important prognostic informations and their use has been associated with improved ability to classify AML further and also to predict disease outcomes $[55,56]$. A recent study using DNA microarray platforms in

344 patients described 16 epigenetically distinct groups, nine of which were associated with specific molecular subgroups of AML (CEBPA, NPM1, AML-ETO1, CBFb-MYH11 and PML-RARA) [57]. A number of recent reports have also identified aberrant methylation profiling in AML associated with several molecular mutations including EVI1 [58], MLL [59] and CEBPA [60]. There are also novel approaches such as the use of deep sequencing platforms that can provide a more comprehensive coverage of methylation profiling in cancer samples. As a proof of principle, whole methylome sequencing studies in AML patients have been reported before and after hypomethylation therapy with decitabine [61].

\section{Molecular aberration in AML}

The discovery and application of molecular biology has been able in the last 10 years to describe recurrent molecular abnormalities in $\mathrm{CN}$ AML. Moreover these mutation has been able to refine the cytogenetical based prognostic models and to improve our understanding of AML. At present, an ever growing number of recurrent mutation are being reported and implicated in the pathogenesis of AML. Here, we will discuss the most important mutations, their associated clinical features, impact on prognosis and directions for future targeted therapy. A complete review of all the single mutations reported in the current literature is beyond the scope of this manuscript, which will focus on the more frequent mutations and on those, among the rare ones, whose prognostic significance has been studied in the context of an homogenous cohort.

\section{Flt3}

Fms-related tyrosine kinase 3 is a type 3 receptor tyrosine kinase normally present on normal bone marrow progenitor cells, whose expression is lost upon maturation [62]. The receptor consists of an extracellular domain composed of five immunoglobulin-like domains, one trans-membrane region, and a cytoplasmic kinase domain split into two parts by a kinase-insert domain. The receptor is activated by binding of the Flt 3 ligand to the extracellular domain, which induces homodimer formation in the plasma membrane leading to autophosphorylation of the receptor. The activated receptor kinase subsequently phosphorylates and activates multiple cytoplasmic effector molecules in pathways involved in apoptosis, proliferation, and differentiation of hematopoietic cells in bone marrow. Mutations in FLT3 gene were one of the first molecular abnormalities to be described and one of the more frequent in CN-AMLs. FLT3 is expressed on AML cells in at least $70 \%$ of cases, and approximately one-third of AML patients harbor activating mutations of FLT3, including internal tandem duplications (ITDs) in 25\% and point mutations in 5\%, resulting in constitutive activation of FLT3 signaling. The presence of the FLT3-ITD mutation, either as a sole abnormality or in conjunction with other gene mutations, commonly nucleophosmin (NPM 1) and CCAAT/Enhancer Binding Protein (CEBPA), has a well-recognized adverse prognostic impact on disease outcomes, with short, disease-free survival (DFS) following standard AML chemotherapy $[63,64]$. As such, molecularly targeted therapies directed at inhibiting FLT3 signaling have been an attractive treatment option to improve disease outcomes in this ill-fated patient subset. Phase I/II trials of single-agent lestaurtinib (CEP701), midostaurin (PKC 412) and sorafenib, demonstrated that these agents were generally well tolerated with more than $70 \%$ of patients achieving some degree of hematologic improvement, as evidenced by reduction in blood and/or bone marrow blasts [65-67]. However, these responses were incomplete and transient, possibly due to high plasma protein binding activity [68], cell cycle inhibition and multikinase inhibition that may result in off-target effects and toxicities $[69,70]$. Besides, the evaluation of these agents in combination with standard chemotherapy regimens leads to incongruous results [70,71]. A possible explanation of these discrepancies is the timing of sorafenib treatment. Actually the levels of Flt3 ligand increases shortly after an intensive chemotherapy, leading to a competitive displacement of the inhibitor. Better results have been reported in a recent paper from the MD Andreson Cancer Center with the association of sorafenib and azacytidine in elderly relapsed or refractory patients [72]. The treatment resulted in $46 \%$ overall response rate (ORR) with $27 \%$ 
complete response $(\mathrm{CR})$ with a median remission duration of 2.3 months (range,1-12.2 months), without increasing toxicities [72] Notwithstanding, FLT3 inhibition remains an important therapeutic target that is the subject of ongoing studies.

\section{NPM1}

This gene encodes a phosphoprotein which moves between the nucleus and the cytoplasm. The gene product is thought to be involved in several processes including regulation of the ARF/p53 pathway. Mutations involving exon 12 within the C-terminal domain of the nucleophosmin gene, NPM1, have been uncovered in approximately one-third of newly diagnosed cases of de novo AML, and comprise the majority of molecular abnormalities appreciated in this subset of patients [73]. Such mutations result in abnormal cytoplasmic localization of the predominantly nucleolar nucleophosmin protein, ultimately leading to abrogation of the activity of key tumor suppressor proteins that are required to be in the nucleus in order to perform their normal function [73,74]. Moreover, NPM1 mutated AML is associated with distinctive biologic and clinical features including older age, female predominance, multi-lineage involvement, mainly FAB M4/M5 morphology, extra-medullary disease, high blast percentage, increased white blood cell counts and lack of CD34 expression [74]. As an isolated molecular abnormality, NPM1 is associated with a highly favorable prognosis, with CR rates between $70-80 \%$ and PFS and OS similar to those in CBF mutated AML $[75,76]$; however, concurrent FLT3-ITD mutations are present in onethird of cases and counteract the positive prognostic impact of the NPM1 mutation [3,76]. Selective inhibitors of nuclear export (SINEs), which bind to and inhibit the activity of the exportin-1 (XPO1) receptor, have shown promising results in preclinical and clinical studies of AML patients [77]. This represents a potentially novel treatment strategy in patients whose leukemia is characterized by mutations that alter normal nuclear export. Moreover, Patel et al. [78] reported a significant survival improvement in NPM1 mutated patients when high dose daunorubicin was employed during induction.

\section{CCAAT/enhancer binding protein alpha (CEBPA)}

Intact functioning CEBPA gene is essential for normal granulocytic differentiation and as a consequence, all CEBPA mutations impairs normal myeloid differentiation. This gene encodes a transcription factor that contains a basic leucine zipper (bZIP) domain and recognizes the CCAAT motif in the promoters of target genes. The encoded protein functions in homodimers and also heterodimers with CCAAT/enhancer-binding proteins beta and gamma. Activity of this protein can modulate the expression of genes involved in cell cycle regulation as well as in body weight homeostasis. Overall CEBPA is mutated in $5-10 \%$ of de novo AML and in up to $15 \%$ of CN-AML cases $[3,79]$. Initially the mere presence of such mutation was reported as a positive prognostic factor, excluding the cases with co-occurring Flt3 mutations $[79,80]$. However, subsequent studies showed that the positive impact on overall survival (OS) is limited to the CEBPA double mutated (CEBPAdm) cases only $[81,82]$. More than $70 \%$ CEBPAdm cases are CN-AML. Concomitant GATA1 and WT1 mutations are found more often in double mutants, while FLT3-ITD, NPM1, ASXL1 and RUNX1 are more commonly associated with single mutations, possibly contributing to the poorer prognostic effect of CEBPAsm [83]. GATA2 mutations have also been reported in approximately $20 \%$ of cases with CEBPAdm and appear to have a favorable impact on patients with intermediate risk AML [84], while concurrent TET2 mutations are associated with a significantly worse overall survival compared to TET2 wild-type cases [85]. As a result several authors support the classification of AML with CEBPAdm as a separate entity with a characteristic and specific gene signature, also supporting a separate designation [86]. Despite the positive effect on OS, recent evidences show that RFS is improved with autologous or allogeneic transplant in CR1, compared to chemotherapy only [87]. Accordingly a recent retrospective evaluation of CEBPAdm patients, treated according to different HOVOLON/SAAK and AMLSG protocols, reports a better PFS and LFS for those transplanted in CR1 but no difference in OS, underling that CEBPAdm AML retains an high sensibility to re-induction chemotherapy, allowing an individually based choice between to perform transplant or not in CR1 [88].

\section{KIT}

This gene encodes the human homolog of the proto-oncogene c-kit. C-kit was first identified as the cellular homolog of the feline sarcoma viral oncogene v-kit. This protein is a type 3 transmembrane receptor for MGF (mast cell growth factor, also known as stem cell factor). Acting as cell-surface receptor for the cytokine KITLG/SCFand plays an essential role in the regulation of cell survival and proliferation, hematopoiesis, stem cell maintenance, gametogenesis, mast cell development, migration and function, and in melanogenesis. In response to KITLG/SCF binding, KIT can activate several signaling pathways. The discovery of activating c-KIT receptor tyrosine kinase mutations in CBF-leukemias, [inv(16)(p13.q22) or $\mathrm{t}(8 ; 21)(\mathrm{q} 22 ; 22)]$, has helped to refine prognosis for patients with what is traditionally considered good-risk leukemia [89]. C-KIT mutations have been consistently shown, in several series, to portend a worse OS and PFS, particularly in patients with $t(8 ; 21)$ [90-92]. Studies investigating the use of c-KIT inhibitors, such as imatinib either alone or in combination with chemotherapy, have produced promising results [93-95]; however, further exploration of this and other KIT inhibitors continue to be underway.

\section{RUNX1}

The gene codifies the alpha subunit of Core binding factor (CBF). $\mathrm{CBF}$ is a heterodimeric transcription factor that binds to the core element of many enhancers and promoters. The protein encoded by this gene is thought to be involved in the development of normal hematopoiesis. The AML Study Group recently conducted a comprehensive analysis of clinical features associated with RUNX1 mutations in a group of $945 \mathrm{AML}$ patients [96]. These mutations have been shown to be present in approximately $5 \%$ of AML cases and were more prevalent in patients with intermediate-risk disease and virtually absent in core-binding factor leukemias, where in turn RUNX1 is the partner gene in $t(8 ; 21)$. In this series the mutations co-occur with MLL-PTD and IDH1/2 and were associated with poor prognosis, including chemotherapy resistance, and shortened EFS, RFS and OS. Moreover the presence of the mutation correlated with age $>60$ years, conferring also in the elderly subgoup a poor prognosis. As such, RUNX1 mutations seem to have an independent prognostic effect on OS $[96,97]$. Lastly they aremutually exclusive of NPM1 and CEBPA mutations and expression profiling demonstrated up-regulation of genes typically appreciated in primitive hematopoietic stem cells and B-cell progenitors [22]. Initial studies support the use of allogeneic stem cell transplant in patients with these mutations [96]. 


\section{RAS}

The Ras oncogene family, whose members are related to the transforming genes of mammalian sarcoma retroviruses, encodes products normally involved in signal transduction pathways. These proteins can bind GTP and GDP, and they have intrinsic GTPase activity. Activating mutations of RAS, either KRAS or NRAS, constitute approximately $20 \%$ of detected mutations in AML [98], especially in CBF-AML (particularly inv (16)). However, they do not appear to carry any major prognostic significance in terms of DFS, EFS or OS $[3,99]$. It has been shown that activating mutations of NRAS potentiate survival of leukemia cells by inhibiting apoptosis and reducing differentiation of AML cells, suggesting a possible mechanistic pathway for leukemogenesis and a potential therapeutic target [100]. Interestingly, the Cancer and Leukemia Group B study group (CALGB) recently demonstrated that patients with AML associated with RAS mutations derived the greatest benefit from high, rather than low, dose cytarabine treatment in terms of relapse risk [101] thereby suggesting that higher drug doses should be used in patients with these mutations.

\section{Additional sex-comb like 1 (ASXL1)}

This gene is similar to the Drosophila additional sex combs gene, which encodes a chromatin-binding protein required for normal determination of segment identity in the developing embryo. The protein is a member of the Polycomb group of proteins, which are necessary for the maintenance of stable repression of homeotic and other loci. The protein is thought to disrupt chromatin in localized areas, enhancing transcription of certain genes while repressing the transcription of other genes. The protein encoded by this gene functions as a ligand-dependent co-activator for retinoic acid receptor in cooperation with nuclear receptor coactivator 1. Mutations of exon 12 within ASXL1 gene have emerged as relatively new molecular aberrations in AML and are reported in approximately $17 \%$ of de novo disease and in up to $30 \%$ of cases with associated cytogenetic abnormalities [102]. AML with associated ASXL1 mutations carries distinctive features, including older age, male predominance, frequent association with antecedent MDS, trisomy 8 and RUNX1 mutations, as well as HLA-DR and CD34 expression [103,104]. They have also been shown to be mutually exclusive of NPM1 mutations and have an inverse association with FLT3-ITD mutations [23,104]. ASXL1 mutations, when present, confer a worse prognosis; several series have demonstrated lower complete remission rates, EFS and OS in patients with these mutations [23,102-105], and, as such, they have been shown to be an independent prognostic factor for overall survival.

\section{Isocitrate dehydrogenase 1 and 2 mutations (IDH1/IDH2)}

Normally IDH1 and 2 catalyze the oxidative decarboxylation of isocitrate to ketoglutate. The ketoglurate acts as a co-substrate for dioxygenases and other cellular enzymes. IDH1/IDH2, like ASXL1, have also been newly regarded as frequent molecular aberrations in AML and are reported in approximately $30 \%$ of CN-AML cases [106]. Different point mutation have been described in AML but all result in the acquisition of a novel metabolic function, leading to the production of

2-hydroxyglutarate (instead of ketoglutarate), deregulating the normal TET2 function. As a consequence the plasmatic levels of 2 hydroxyglutarate has recently been proposed as an alternative tool to the direct sequencing [105]. The real prognostic impact is still a matter of debate. In the early CALGB study, where the frequency and prognostic impact of these mutations were assessed in a group of 358 patients with CN-AML [106], IDH1 mutations were seen in $14 \%$ of patients, compared to $19 \%$ IDH2 mutated patients, and were associated with younger age and concomitant occurrence in patients with molecularly favorable disease based on NPM1 and FLT3-ITD mutation status. Both IDH1 and 2 mutations conferred an inferior disease free survival (DFS) and complete remission (CR) rates. A separate study confirmed the poor impact on RFS and OS showing that these mutation counterbalance the positive prognostic impact of NPM1mutation among FLT3-ITD negative diseases [107,108]. However, recently, two different studies questioned these data. Patel et al. demonstrated that the real impact of IDH1/2 mutations can only be estimated in the context of a wider genomic evaluation of AML. The Authors were able to describe both a positive impact of the IDH2 R140 mutation in the whole ECOG E1900 trial population, and a better outcome than patients with inv(16)- or $\mathrm{t}(8: 21)$-positive AML among NPM1/IDH mutant patients, suggesting that the last one represents a favorable-risk AML subset defined by a specific mutational genotype [78]. Similarly, the the MRC reported similar results in IDH R140 and in NPM1/IDH2 R140 double mutated young patients [108].

\section{Ten-eleven translocation 2 (TET2)}

TET2 is a methylcytosine dioxygenase that catalyzes the conversion of methylcytosine to 5-hydroxymethylcytosine, leading to the demethylation of $\mathrm{CpG}$ islands and so to the derepression of gene's transcription. TET2 mutations have been identified in approximately $30 \%$ of AML cases by deep sequencing [109], usually in combination with other molecular abnormalities, except for IDH1/IDH2 mutations with which they have been shown to be mutually exclusive [110]. It has been reported to occur in $>10 \%$ of younger AML patients [110]. When present in NPM1 mutated, FLT3-ITD wild-type disease (defined as a favorable risk group, according to European Leukemia Net classification), TET2 mutations confer a poor prognostic impact $[26,109]$.

\section{DNA (Cytosine-5-)-Methyltransferase 3 Alpha (DNMT3A)}

DNMT3A is normally required for genome-wide de novo methylation and is essential for the establishment of DNA methylation patterns during development and differentiation. DNA methylation is coordinated with methylation of histones. It modifies DNA in a nonprocessive manner and also methylates non-CpG sites. DNMT3A mutations, which affect the DNA methyltransferase enzymes and subsequent epigenetic modulation, have been described in approximately $20 \%$ of patients with de novo AML and are seen almost exclusively in intermediate disease; they are conspicuously absent in cytogenetically favorable disease [111]. A recent large study conducted by the AML Study Group characterized clinical features and disease outcomes in a group of 1.770 AML patients less than 60 years of age. DNMT3A mutations were more commonly appreciated in older patients (median age 50 years), and in CN-AML. It was seen concomitantly with NPM1, FLT3-ITD and IDH1/IDH2 mutations as well, but did not seem to affect any major survival endpoint [112], although in prior reports, the presence of DNMT3A mutations were found to be associated with worse overall survival, compared to those without the mutation (12 months vs. 41 months) [111-113]. 


\section{PHD Finger Protein 6 (PHF6) mutations}

This gene is a member of the plant homeodomain (PHD)-like finger (PHF) family. It encodes a protein with two PHD-type zinc finger domains, indicating a potential role in transcriptional regulation, that localizes to the nucleolus. Mutations in PHF6 were first identified in T-cell acute lymphoblastic leukemia using nextgeneration sequencing of the $\mathrm{X}$ chromosome [114]. The majority of mutations are nonsense or frameshift alleles, again consistent with a loss-of-function role for PHF6 in leukemogenesis. Subsequent candidate gene sequencing of PHF6 in AML revealed that approximately $3 \%$ of patients harbored PHF6 mutations [114]. PHF6 is a plant homeodomain finger-containing protein, an important highly conserved domain in recognizing protein-DNA interactions and histone modifications. In T-cell acute lymphoblastic leukemia, loss of PHF6 is associated with expression of the oncogenes TLX and TLX3, and the genetic data are consistent with PHF6 functioning as a $\mathrm{X}$-linked tumor suppressor. The role of PHF6 mutations in AML pathogenesis has yet to be elucidated.

\section{Prognostic relevance of newly identified genes: Practical points}

Although a series of elegant studies over the past decade have identified a large set of mutations and overexpressed genes with prognostic relevance in AML, in the clinical setting, most AML centers still use cytogenetic based stratification together with a relatively small set of gene-based tests to assign risk in AML and to determine postremission therapy. The relative scarce use of clinically biomarkers is due to several factors. First, most biomarker studies focus on a specific genetic lesion and its prognostic relevance without considering the whole set of known mutations in parallel to determine, which mutations predict outcome independently in AML. Second, most studies consider each mutant allele as a distinct variable without considering complex genotypes in which the presence/absence of multiple genomic mutations has different effects on outcome than individual mutations by themselves. Third, many studies have focused on mutational "hotspots" or have used less sensitive techniques to identify loss-of-function mutations in large tumor suppressors. Finally and most importantly, until recently, most studies of AML were relatively small in size and/or were not derived from clinical trial cohorts in which the effects of treatment on outcome can be controlled and investigated.

With these limitations in mind and given the increasing number of genetic abnormalities that have been identified in AML patients, it has become important to determine the prognostic relevance of all known recurrent genetic abnormalities in a uniformly treated AML patient cohort. The largest such study to date used high-throughput sequencing of TET2, ASXL1, DNMT3A, PHF6, WT1, TP53, RUNX1, EZH2PTEN, FLT3, NPM1, CEBPA, HRAS, KRAS, NRAS, KIT, IDH1, and IDH2 in 502 patients from the Eastern Cooperative Oncology Group (ECOG) E1900 trial [78]. This trial evaluated the anthracycline dose intensification during induction therapy. A total of 657 patients between the ages of 17 and 60 years with de novo AML were randomized to receive standard doses cytarbine with either $45 \mathrm{mg} / \mathrm{m} 2$ of daunorubicin or $90 \mathrm{mg} / \mathrm{m} 2$ of daunorubicin. This large, homogeneously treated patient cohort allowed for extensive mutational profiling from diagnostic samples and correlation with outcome, including DFS and OS and response to induction therapy. Integrated genetic analysis revealed 3 recently identified genes with prognostic importance in the total cohort of AML patients.
Specifically, IDH2 R140 mutations, but not IDH2 R172 mutations or IDH1 mutations, were associated with improved OS in the entire E1900 cohort, this suggesting that there are important qualitative and/or quantitative differences in the various IDH1/2 mutations in AML, and that these allele-specific differences in biology have relevance to outcome in AML. In addition, mutations in ASXL1 and PHF6 were associated with adverse OS in the whole cohort, suggesting that these relatively rare AML alleles mark a subset of patients with adverse outcome. Moreover, data from the MRC in younger adults treated with aggressive therapy (induction followed by allogeneic or autologous transplantation) described favorable outcome with IDH2 R140 mutations or with double NPM1/IDH2 mutations [108], suggesting that cohort size, age, and treatment approach have significant effects on prognostication in AML.

Although the identification of single gene mutations with impact on overall outcome is momentous, the main goal of molecular studies should be to inform and improve prognostic algorithms in the 3 broad cytogenetic risk categories of AML. However, to date, most studies have failed to identify robust predictors that modify outcome in patients with favorable or unfavorable cytogenetic risk, suggesting that chromosomal lesions remain the best predictor of outcome for the $40 \%$ of AML patients with favorable or unfavorable karyotypic risk.

In contrast, mutational studies have been able to better refine prognosis in patients with intermediate-risk and/or normal karyotype AML. Previous studies have suggested that mutational analysis of CEBPA, NPM1, and FLT3-ITD can be used to risk-stratify intermediate-risk AML patients [3]. However, more extensive mutational analysis better discriminates intermediate-risk AML patients into robust, clinically relevant risk groups [78]. As demonstrated by E1900 cohort, we can divide FLT3-ITD-negative intermediate-risk AML into 3 distinct risk subgroups, basing on mutational status. FLT3-ITD-negative, NPM1/IDH mutant patients have outcomes that are better than patients with inv (16)- or $t(8: 21)$ positive AML, suggesting that this represents a favorable-risk AML subset defined by a specific mutational genotype. In contrast, FLT3ITD-negative NPM1 mutant patients without concurrent IDH mutations have a much less favorable outcome. Most importantly, the presence of poor-risk mutations, specifically TET2, ASXL1, PHF6, and/or MLL-PTD is associated with very adverse OS for FLT3-ITD wild-type, intermediate-risk patients. These data suggest that NPM1 mutational status alone does not define a favorable subset of intermediate-risk AML, and that the presence or absence of additional disease alleles defines relapse risk in FLT3-ITD wild-type, intermediate-risk AML [78]. In addition, mutational studies also allow a further subdivision in FLT3-ITD-positive intermediate-risk patients. Among FLT3-ITD mutant patients, concurrent mutations in TET2, DNMT3A, MLL-PTD, or trisomy (8) were associated with very poor outcome. This is a relatively large subset of patients and approximately $47 \%$ of the total intermediate-risk FLT3-ITD patient subset fall into this very-high-risk subset. Therefore, the category of intermediate-risk FLT3-ITD patients with 1 of these 4 mutations forms a new subset of FLT3-ITD, intermediate-risk AML patients and this may have important implications for treatment decisions. Lastly, patients who have the FLT3-ITD mutation without the addition of any of the 4 genetic abnormalities actually have a similar outcome to FLT3-ITD/ CEBPa double-mutant patients [78].

These data clearly demonstrate that intermediate-risk patients can be reclassified as having favorable, intermediate, or poor risk based on the mutational status of 9 genes (Figure 4). 


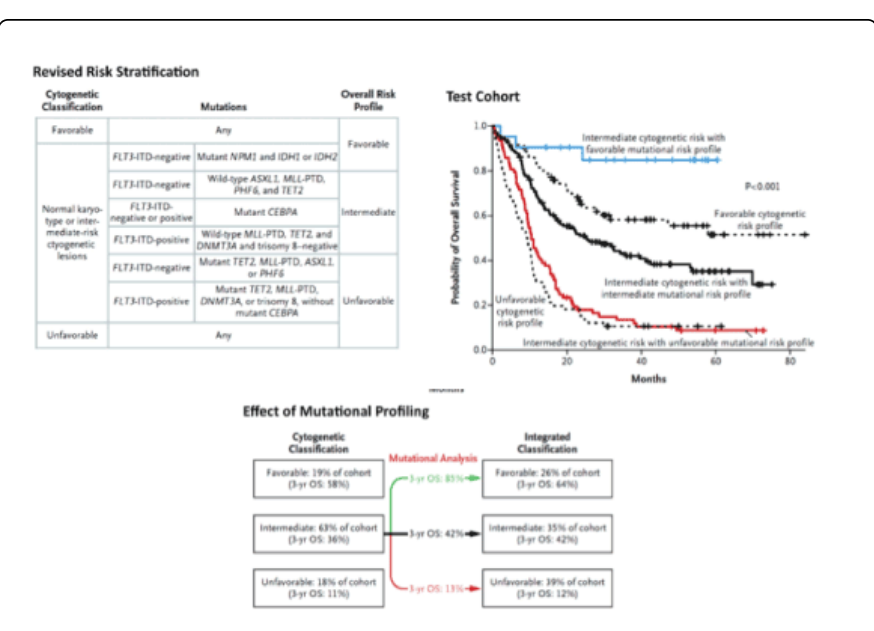

Figure 4: Revised classification of CN-AML, according to 9 genes' mutational status (reproduced from Patel et al. NEJM 2012 [76]).

All this has important clinical implications, considering that mutationally defined favorable patients have a better outcome with standard induction and consolidation than even patients with CBFAML. In contrast, patients with mutationally defined adverse-risk AML have an outcome similar to patients with adverse karyotypic risk, and standard therapies are not sufficient to cure the majority of these patients. We affirm that future clinical trials should aim to identify genetically defined high-risk patients to offer these patients novel therapies early in their disease course, including novel therapeutic approaches to induction, consolidation, and maintenance therapy in an effort to reduce relapse and increase cure. Moreover these studies will be the platform for the validation of the molecular classification in other large, homogeneously treated patient cohorts and will resolve the inconsistency between different studies on specific genetic alterations.

\section{Conclusion}

In the last few years we gained a lot of new data on AMLs' biology, which translated both in the identification of new subtypes and in an improvement of the classical prognostic classification [1]. However there is still a lot of work to do in particular if we look to SNP, microRNA expression and GEP arrays. If it is true that these technique are efficient tools for implementing the current knowledge in leukemia field, we are far away from the introduction in the clinical practice due to the lack of standardization and the conflicting results published to date. This rises one practical question: How can we solve this? The only way is to build well designed study comparing the standard diagnostic approach to the new technology, as the ELN did in the MILE study [3]. With such methodology we can learn both how, when and why to use the new techniques and what a specific result really means. Last but not least, all this path will take us in facing two different challenges: determining the prognostic relevance and impact on treatment outcome of single and multiple concurring mutations; identifying new molecular targets for future biological therapy. Maybe in near future results from two ongoing study one from Israel in AML, MDS and Myeloproliferative Neoplasms and the other one in therapy related AML from MD Anderson (NCT02084563 and NCT00525746 respectively), will hopefully help in answering the first question.

\section{References}

1. Byrd JC, Mrózek K, Dodge RK, Carroll AJ, Edwards CG, et al. (2002) Pretreatment cytogenetic abnormalities are predictive of induction success, cumulative incidence of relapse, and overall survival in adult patients with de novo acute myeloid leukemia: results from Cancer and Leukemia Group B (CALGB 8461). Blood 100: 4325-4336.

2. Grimwade D, Walker H, Oliver F, Wheatley K, Harrison C, Harrison G, et al. (1998) The importance of diagnostic cytogenetics on outcome in AML: analysis of ,612 patients entered into the MRC AML 10 trial. The Medical Research Council Adult and Childrenâ $€^{m w}$ s Leukaemia Working Parties. Blood 92: 2322-2333.

3. Schlenk RF, Döhner K, Krauter J, Fröhling S, Corbacioglu A, et al. (2008) Mutations and treatment outcome in cytogenetically normal acute myeloid leukemia. N Engl J Med 358: 1909-1918.

4. Vardiman JW, Thiele J, Arber DA, Brunning RD, Borowitz MJ, et al. (2009) The 2008 revision of the World Health Organization (WHO) classification of myeloid neoplasms and acute leukemia: rationale and important changes. Blood 114: 937-951.

5. Bullinger L, Döhner K, Bair E, Fröhling S, Schlenk RF, et al. (2004) Use of gene-expression profiling to identify prognostic subclasses in adult acute myeloid leukemia. N Engl J Med 350: 1605-1616.

6. Valk PJ, Verhaak RG, Beijen MA, Erpelinck CA, Barjesteh van Waalwijk van Doorn-Khosrovani S, et al. (2004) Prognostically useful geneexpression profiles in acute myeloid leukemia. N Engl J Med 350: 1617-1628.

7. Bullinger L, Döhner K, Kranz R, Stirner C, Fröhling S, et al. (2008) An FLT3 gene-expression signature predicts clinical outcome in normal karyotype AML. Blood 111: 4490-4495.

8. de Jonge HJ, Woolthuis CM, Vos AZ, Mulder A, van den Berg E, et al. (2011) Gene expression profiling in the leukemic stem cell-enriched $\mathrm{CD} 34+$ fraction identifies target genes that predict prognosis in normal karyotype AML. Leukemia 25: 1825-1833.

9. Lo MC, Peterson LF, Yan M, Cong X, Jin F, et al. (2012) Combined gene expression and DNA occupancy profiling identifies potential therapeutic targets of $\mathrm{t}(8 ; 21)$ AML. Blood 120: 1473-1484.

10. Verhaak RG, Wouters BJ, Erpelinck CA, Abbas S, Beverloo HB, et al. (2009) Prediction of molecular subtypes in acute myeloid leukemia based on gene expression profiling. Haematologica 94: 131-134.

11. Rapin N, Bagger FO, Jendholm J, Mora-Jensen H, Krogh A, et al. (2014) Comparing cancer vs normal gene expression profiles identifies new disease entities and common transcriptional programs in AML patients. Blood 123: 894-904.

12. Metzeler KH, Hummel M, Bloomfield CD, Spiekermann K, Braess J, et al. (2008) An 86-probe-set gene-expression signature predicts survival in cytogenetically normal acute myeloid leukemia. Blood 112: 4193-4201.

13. Rao AV, Valk PJ, Metzeler KH, Acharya CR, Tuchman SA, et al. (2009) Age-specific differences in oncogenic pathway dysregulation and anthracycline sensitivity in patients with acute myeloid leukemia. J Clin Oncol 27: 5580-5586.

14. Haferlach T, Kohlmann A, Wieczorek L, Basso G, Kronnie GT, Bene MC, et al. (2010) Clinical utility of microarray-based gene expression profiling in the diagnosis and subclassification of leukemia: report from the International Microarray Innovations in Leukemia Study Group. J Clin Oncol Off J Am Soc Clin Oncol 28: 2529-2537.

15. Mills KI, Gilkes AF, Hernandez JM, Hofmann WK, Kohlmann A, et al. (2007) A molecular classification of leukaemia reveals MDS as a disease continuum with non-leukaemia and AML sub groups. Haematologica 92: 165.

16. Mills KI, Kohlmann A, Williams PM, Wieczorek L, Liu WM, et al. (2009) Microarray-based classifiers and prognosis models identify subgroups with distinct clinical outcomes and high risk of AML transformation of myelodysplastic syndrome. Blood 114: 1063-1072.

17. Jongen-Lavrencic M, Sun SM, Dijkstra MK, Valk PJ, Löwenberg B (2008) MicroRNA expression profiling in relation to the genetic heterogeneity of acute myeloid leukemia. Blood 111: 5078-5085. 
18. Dixon-McIver A, East P, Mein CA, Cazier JB, Molloy G, et al. (2008) Distinctive patterns of microRNA expression associated with karyotype in acute myeloid leukaemia. PLoS One 3: e2141.

19. Li Z, Lu J, Sun M, Mi S, Zhang H, et al. (2008) Distinct microRNA expression profiles in acute myeloid leukemia with common translocations. Proc Natl Acad Sci U S A 105: 15535-15540.

20. Garzon R, Garofalo M, Martelli MP, Briesewitz R, Wang L, et al. (2008) Distinctive microRNA signature of acute myeloid leukemia bearing cytoplasmic mutated nucleophosmin. Proc Natl Acad Sci U S A 105: 3945-3950.

21. Marcucci G, Maharry K, Radmacher MD, Mrózek K, Vukosavljevic T, et al. (2008) Prognostic significance of, and gene and microRNA expression signatures associated with, CEBPA mutations in cytogenetically norma acute myeloid leukemia with high-risk molecular features: a Cancer and Leukemia Group B Study. J Clin Oncol 26: 5078-5087.

22. Mendler JH, Maharry K, Radmacher MD, Mrózek K, Becker H, et al. (2012) RUNX1 mutations are associated with poor outcome in younger and older patients with cytogenetically normal acute myeloid leukemia and with distinct gene and MicroRNA expression signatures. J Clin Oncol 30: 3109-3118.

23. Metzeler KH, Becker H, Maharry K, Radmacher MD, Kohlschmidt J, et al. (2011) ASXL1 mutations identify a high-risk subgroup of older patients with primary cytogenetically normal AML within the ELN Favorable genetic category. Blood 118: 6920-6929.

24. Marcucci G, Metzeler KH, Schwind S, Becker H, Maharry K, et al. (2012) Age-related prognostic impact of different types of DNMT3A mutations in adults with primary cytogenetically normal acute myeloid leukemia. J Clin Oncol 30: 742-750.

25. Lück SC, Russ AC, Du J, Gaidzik V, Schlenk RF, et al. (2010) KIT mutations confer a distinct gene expression signature in core binding factor leukaemia. Br J Haematol 148: 925-937.

26. Metzeler KH, Maharry K, Radmacher MD, Mrózek K, Margeson D, et al. (2011) TET2 mutations improve the new European LeukemiaNet risk classification of acute myeloid leukemia: a Cancer and Leukemia Group B study. J Clin Oncol 29: 1373-1381.

27. Schwind S, Marcucci G, Kohlschmidt J, Radmacher MD, Mrózek K, et al. (2011) Low expression of MN1 associates with better treatment response in older patients with de novo cytogenetically normal acute myeloid leukemia. Blood 118: 4188-4198.

28. Schwind S, Marcucci G, Maharry K, Radmacher MD, MrozekK, et al. (2010) BAALC and ERG expression levels are associated with outcome and distinct gene and micro-RNA expression profiles in older patients with de novo cytogenetically normal acute myeloid leukemia: a Cancer and Leukemia Group B study. Blood 116: 5660-5669.

29. Marcucci G, Radmacher MD, Mrózek K, Bloomfield CD (2009) MicroRNA expression in acute myeloid leukemia. Curr Hematol Malig Rep 4: 83-88.

30. Garzon R, Volinia S, Liu CG, Fernandez-Cymering C, Palumbo T, et al. (2008) MicroRNA signatures associated with cytogenetics and prognosis in acute myeloid leukemia. Blood 111: 3183-3189.

31. Marcucci G, Radmacher MD, Maharry K, Mrózek K, Ruppert AS, et al. (2008) MicroRNA expression in cytogenetically normal acute myeloid leukemia. N Engl J Med 358: 1919-1928.

32. de Leeuw DC, Denkers F, Olthof MC, Rutten AP, Pouwels W, et al. (2014) Attenuation of microRNA-126 expression that drives CD34+38stem/progenitor cells in acute myeloid leukemia leads to tumor eradication. Cancer Res 74: 2094-2105.

33. Marcucci G, Maharry KS, Metzeler KH, Volinia S, Wu YZ, et al. (2013) Clinical role of microRNAs in cytogenetically normal acute myeloid leukemia: miR-155 upregulation independently identifies high-risk patients. J Clin Oncol 31: 2086-2093.

34. Díaz-Beyá M, Brunet S, Nomdedéu J, Tejero R, Díaz T, et al. (2014) MicroRNA expression at diagnosis adds relevant prognostic information to molecular categorization in patients with intermediate-risk cytogenetic acute myeloid leukemia. Leukemia 28: 804-812.
35. Redon R, Ishikawa S, Fitch KR, Feuk L, Perry GH, et al. (2006) Global variation in copy number in the human genome. Nature 444: 444-454.

36. Zhang F, Gu W, Hurles ME, Lupski JR (2009) Copy number variation in human health, disease, and evolution. Annu Rev Genomics Hum Genet 10: 451-481.

37. Walter MJ, Payton JE, Ries RE, Shannon WD, Deshmukh H, et al. (2009) Acquired copy number alterations in adult acute myeloid leukemia genomes. Proc Natl Acad Sci U S A 106: 12950-12955.

38. Radtke I, Mullighan CG, Ishii M, Su X, Cheng J, et al. (2009) Genomic analysis reveals few genetic alterations in pediatric acute myeloid leukemia. Proc Natl Acad Sci U S A 106: 12944-12949.

39. Gupta M, Raghavan M, Gale RE, Chelala C, Allen C, et al. (2008) Novel regions of acquired uniparental disomy discovered in acute myeloid leukemia. Genes Chromosomes Cancer 47: 729-739.

40. Heinrichs S, Kulkarni RV, Bueso-Ramos CE, Levine RL, Loh ML, et al. (2009) Accurate detection of uniparental disomy and microdeletions by SNP array analysis in myelodysplastic syndromes with normal cytogenetics. Leukemia 23: 1605-1613.

41. Tiu RV, Gondek LP, OKeefe CL, Huh J, Sekeres MA, et al. (2009) New lesions detected by single nucleotide polymorphism array-based chromosomal analysis have important clinical impact in acute myeloid leukemia. JCO 27: 5219-5226.

42. Yi JH, Huh J, Kim HJ, Kim SH, Kim HJ, et al. (2011) Adverse prognostic impact of abnormal lesions detected by genome-wide single nucleotide polymorphism array-based karyotyping analysis in acute myeloid leukemia with normal karyotype. JCO 29: 4702-47028.

43. López-Pedrera C, Villalba JM, Siendones E, Barbarroja N, Gómez-Díaz C, et al. (2006) Proteomic analysis of acute myeloid leukemia: Identification of potential early biomarkers and therapeutic targets. Proteomics 6 Suppl 1: S293-299.

44. Ng PC, Kirkness EF (2010) Whole genome sequencing. Methods Mol Biol 628: 215-226.

45. Rabbani B, Tekin M, Mahdieh N (2014) The promise of whole-exome sequencing in medical genetics. J Hum Genet 59: 5-15.

46. Yang Q, Hua J, Wang L, Xu B, Zhang H, et al. (2013) MicroRNA and piRNA profiles in normal human testis detected by next generation sequencing. PLoS One 8: e66809.

47. Wang Z, Gerstein M, Snyder M (2009) RNA-Seq: a revolutionary tool for transcriptomics. Nat Rev Genet 10: 57-63.

48. Mortazavi A, Williams BA, McCue K, Schaeffer L, Wold B (2008) Mapping and quantifying mammalian transcriptomes by RNA-Seq. Nat Methods 5: 621-628.

49. Ley TJ, Mardis ER, Ding L, Fulton B, McLellan MD, et al. (2008) DNA sequencing of a cytogenetically normal acute myeloid leukaemia genome. Nature 456: 66-72.

50. Mardis ER, Ding L, Dooling DJ, Larson DE, McLellan MD, et al. (2009) Recurring mutations found by sequencing an acute myeloid leukemia genome. N Engl J Med 361: 1058-1066.

51. Welch JS, Ley TJ, Link DC, Miller CA, Larson DE, et al. (2012) The origin and evolution of mutations in acute myeloid leukemia. Cell 150: 264-278.

52. Cancer Genome Atlas Research Network (2013) Genomic and epigenomic landscapes of adult de novo acute myeloid leukemia. N Engl J Med 368: 2059-2074.

53. Schoofs T, Müller-Tidow C (2011) DNA methylation as a pathogenic event and as a therapeutic target in AML. Cancer Treat Rev 37 Suppl 1: S13-18.

54. Goodell MA, Godley LA (2013) Perspectives and future directions for epigenetics in hematology. Blood 121: 5131-5137.

55. Bullinger L, Ehrich M, Döhner K, Schlenk RF, Döhner H, et al. (2010) Quantitative DNA methylation predicts survival in adult acute myeloid leukemia. Blood 115: 636-642.

56. Treppendahl MB, Qiu X, Søgaard A, Yang X, Nandrup-Bus C, et al. (2012) Allelic methylation levels of the noncoding VTRNA2-1 located on chromosome 5q31.1 predict outcome in AML. Blood 119: 206-216. 
57. Figueroa ME, Lugthart S, Li Y, Erpelinck-Verschueren C, Deng X, et al. (2010) DNA methylation signatures identify biologically distinct subtypes in acute myeloid leukemia. Cancer Cell 17: 13-27.

58. Lugthart S, Figueroa ME, Bindels E, Skrabanek L, Valk PJ, et al. (2011) Aberrant DNA hypermethylation signature in acute myeloid leukemia directed by EVI1. Blood 117: 234-241.

59. Whitman SP, Hackanson B, Liyanarachchi S, Liu S, Rush LJ, et al. (2008) DNA hypermethylation and epigenetic silencing of the tumor suppressor gene, SLC5A8, in acute myeloid leukemia with the MLL partial tandem duplication. Blood 112: 2013-2016.

60. Lu Y, Chen W, Chen W, Stein A, Weiss LM, et al. (2010) C/EBPA gene mutation and C/EBPA promoter hypermethylation in acute myeloid leukemia with normal cytogenetics. Am J Hematol 85: 426-430.

61. Yan P, Frankhouser D, Murphy M, Tam HH, Rodriguez B, et al. (2012) Genome-wide methylation profiling in decitabine-treated patients with acute myeloid leukemia. Blood 120: 2466-2474.

62. Adolfsson J, Mansson R, Buza-Vidas N, Hultquist A, Liuba K, et al (2005) Identification of Flt3+ lympho-myeloid stem cells lacking erythromegakaryocytic potential a revised road map for adult blood lineage commitment. Cell 121: 295-306.

63. Thiede C, Steudel C, Mohr B, Schaich M, Schäkel U, et al. (2002) Analysis of FLT3-activating mutations in 979 patients with acute myelogenous leukemia: association with FAB subtypes and identification of subgroups with poor prognosis. Blood 99: 4326-4335.

64. Reindl C, Bagrintseva K, Vempati S, Schnittger S, Ellwart JW, et al. (2006) Point mutations in the juxtamembrane domain of FLT3 define a new class of activating mutations in AML. Blood 107: 3700-3707.

65. Stone RM, DeAngelo DJ, Klimek V, Galinsky I, Estey E, et al. (2005) Patients with acute myeloid leukemia and an activating mutation in FLT3 respond to a small-molecule FLT3 tyrosine kinase inhibitor, PKC412. Blood 105: 54-60.

66. Fischer T, Stone RM, Deangelo DJ, Galinsky I, Estey E, et al. (2010) Phase IIB trial of oral Midostaurin (PKC412), the FMS-like tyrosine kinase 3 receptor (FLT3) and multi-targeted kinase inhibitor, in patients with acute myeloid leukemia and high-risk myelodysplastic syndrome with either wild-type or mutated FLT3. J Clin Oncol Off J Am Soc Clin Oncol 28: 4339-4345.

67. Quintas-Cardama A, Kantarjian H, Andreef M, Faderl S, Wright J, et al (2007) Phase I trial of intermittent administration of sorafenib (BAY 43-9006) for patients (pts) with refractory/ relapsed acute myelogenous leukemia (AML). ASCO Meeting Abstracts 25: 7018.

68. Levis M, Pham R, Smith BD, Small D (2004) In vitro studies of a FLT3 inhibitor combined with chemotherapy: sequence of administration is important to achieve synergistic cytotoxic effects. Blood 104: 1145-1150.

69. Levis M, Ravandi F, Wang ES, Baer MR, Perl A, et al. (2011) Results from a randomized trial of salvage chemotherapy followed by lestaurtinib for patients with FLT3 mutant AML in first relapse. Blood 117: 3294-3301.

70. Ravandi F, Cortes JE, Jones D, Faderl S, Garcia-Manero G, et al. (2010) Phase I/II study of combination therapy with sorafenib, idarubicin, and cytarabine in younger patients with acute myeloid leukemia. J Clin Oncol 28: 1856-1862.

71. Serve H, Krug U, Wagner R, Sauerland MC, Heinecke A, et al. (2013) Sorafenib in combination with intensive chemotherapy in elderly patients with acute myeloid leukemia: results from a randomized, placebo-controlled trial. J Clin Oncol 31: 3110-3118.

72. Ravandi F, Alattar ML, Grunwald MR, Rudek MA, Rajkhowa T, et al. (2013) Phase 2 study of azacytidine plus sorafenib in patients with acute myeloid leukemia and FLT-3 internal tandem duplication mutation. Blood 121: 4655-4662.

73. Grisendi S, Mecucci C, Falini B, Pandolfi PP (2006) Nucleophosmin and cancer. Nat Rev Cancer 6: 493-505.

74. Falini B, Mecucci C, Tiacci E, Alcalay M, Rosati R, et al. (2005) Cytoplasmic nucleophosmin in acute myelogenous leukemia with a normal karyotype. N Engl J Med 352: 254-266.

75. Schnittger S, Schoch C, Kern W, Mecucci C, Tschulik C, et al. (2005) Nucleophosmin gene mutations are predictors of favorable prognosis in acute myelogenous leukemia with a normal karyotype. Blood 106: 3733-3739.

76. Gale RE, Green C, Allen C, Mead AJ, Burnett AK, et al. (2008) The impact of FLT3 internal tandem duplication mutant level, number, size, and interaction with NPM1 mutations in a large cohort of young adult patients with acute myeloid leukemia. Blood 111:2776-2784.

77. Ranganathan P, Yu X, Na C, Santhanam R, Shacham S, et al. (2012) Preclinical activity of a novel CRM1 inhibitor in acute myeloid leukemia. Blood 120: 1765-1773.

78. Patel JP, Gönen M, Figueroa ME, Fernandez H, Sun Z, et al. (2012) Prognostic relevance of integrated genetic profiling in acute myeloid leukemia. N Engl J Med 366: 1079-1089.

79. Fröhling S, Schlenk RF, Stolze I, Bihlmayr J, Benner A, et al. (2004) CEBPA mutations in younger adults with acute myeloid leukemia and normal cytogenetics: prognostic relevance and analysis of cooperating mutations. J Clin Oncol 22: 624-633.

80. Preudhomme C, Sagot C, Boissel N, Cayuela JM, Tigaud I, et al. (2002) Favorable prognostic significance of CEBPA mutations in patients with de novo acute myeloid leukemia: a study from the Acute Leukemia French Association (ALFA). Blood 100: 2717-2723.

81. Pabst T, Eyholzer M, Fos J, Mueller BU (2009) Heterogeneity within AML with CEBPA mutations; only CEBPA double mutations, but not single CEBPA mutations are associated with favourable prognosis. $\mathrm{Br} \mathrm{J}$ Cancer 100: 1343-1346.

82. Dufour A, Schneider F, Metzeler KH, Hoster E, Schneider S, et al. (2010) Acute myeloid leukemia with biallelic CEBPA gene mutations and normal karyotype represents a distinct genetic entity associated with a favorable clinical outcome. J Clin Oncol Off J Am Soc Clin Oncol 28: 570-577.

83. Fasan A, Haferlach C, Alpermann T, Jeromin S, Grossmann V, et al (2014) The role of different genetic subtypes of CEBPA mutated AML. Leukemia 28: 794-803.

84. Fasan A, Eder C, Haferlach C, Grossmann V, Kohlmann A, et al. (2013) GATA2 mutations are frequent in intermediate-risk karyotype AML with biallelic CEBPA mutations and are associated with favorable prognosis. Leukemia 27: 482-485.

85. Grossmann V, Haferlach C, Nadarajah N, Fasan A, Weissmann S, et al. (2013) CEBPA double-mutated acute myeloid leukaemia harbours concomitant molecular mutations in $76.8 \%$ of cases with TET2 and GATA2 alterations impacting prognosis. Br J Haematol 161: 649-658.

86. Taskesen E, Bullinger L, Corbacioglu A, Sanders MA, Erpelinck CA, et al. (2011) Prognostic impact, concurrent genetic mutations, and gene expression features of AML with CEBPA mutations in a cohort of 1182 cytogenetically normal AML patients: further evidence for CEBPA double mutant AML as a distinctive disease entity. Blood 117: 2469-2475.

87. Schlenk RF, Dohner K, Mack S, Stoppel M, Kiraly F, et al. (2010) Prospective evaluation of allogeneic hematopoietic stemcell transplantation from matched related and matched unrelated donors in younger adults with high-risk acute myeloid leukemia: German-Austrian trial AMLHD98A. J Clin Oncol. 28: 4642-4648.

88. Schlenk RF, Taskesen E, van Norden Y, Krauter J, Ganser A, et al. (2013) The value of allogeneic and autologous hematopoietic stem cell transplantation in prognostically favorable acute myeloid leukemia with double mutant CEBPA. Blood 122: 1576-1582.

89. Paschka P, Marcucci G, Ruppert AS, Mrózek K, Chen H, et al. (2006) Adverse prognostic significance of KIT mutations in adult acute myeloid leukemia with $\operatorname{inv}(16)$ and $t(8 ; 21)$ : a Cancer and Leukemia Group B Study. J Clin Oncol 24: 3904-3911.

90. Boissel N, Leroy H, Brethon B, Philippe N, de Botton S, et al. (2006) Incidence and prognostic impact of c-Kit, FLT, and Ras gene mutations in core binding factor acute myeloid leukemia (CBF-AML). Leukemia 20: 965-970.

91. Kim HJ, Ahn HK, Jung CW, Moon JH, Park CH, et al. (2013) KIT D816 mutation associates with adverse outcomes in core binding factor acute myeloid leukemia, especially in the subgroup with RUNX1/RUNX1T1 rearrangement. Ann Hematol 92: 163-171. 
92. Schnittger S, Kohl TM, Haferlach T, Kern W, Hiddemann W, et al (2006) KIT-D816 mutations in AML1-ETO-positive AML are associated with impaired event-free and overall survival. Blood 107: 1791-1799.

93. Advani AS, Tiu R, Saunthararajah Y, Maciejewski J, Copelan EA, et al. (2010) A Phase 1 study of imatinib mesylate in combination with cytarabine and daunorubicin for c-kit positive relapsed acute myeloid leukemia. Leuk Res 34: 1622-1626.

94. Brandwein JM, Hedley DW, Chow S, Schimmer AD, Yee KW, et al. (2011) A phase I/II study of imatinib plus reinduction therapy for c-kitpositive relapsed/refractory acute myeloid leukemia: inhibition of Akt activation correlates with complete response. Leukemia 25: 945-952.

95. Kindler T, Breitenbuecher F, Marx A, Beck J, Hess G, et al. (2004) Efficacy and safety of imatinib in adult patients with c-kit-positive acute myeloid leukemia. Blood 103: 3644-3654.

96. Gaidzik VI, Bullinger L, Schlenk RF, Zimmermann AS, Röck J, et al. (2011) RUNX1 mutations in acute myeloid leukemia: results from a comprehensive genetic and clinical analysis from the AML study group. J Clin Oncol 29: 1364-1372.

97. Schnittger S, Dicker F, Kern W, Wendland N, Sundermann J, et al. (2011) RUNX1 mutations are frequent in de novo AML with noncomplex karyotype and confer an unfavorable prognosis. Blood 117: 2348-2357.

98. Goemans BF, Zwaan CM, Miller M, Zimmermann M, Harlow A, et al. (2005) Mutations in KIT and RAS are frequent events in pediatric corebinding factor acute myeloid leukemia. Leukemia 19: 1536-1542.

99. Bacher U, Haferlach T, Schoch C, Kern W, Schnittger S (2006) Implications of NRAS mutations in AML: a study of 2502 patients. Blood 107: 3847-3853.

100. Kim WI, Matise I, Diers MD, Largaespada DA (2009) RAS oncogene suppression induces apoptosis followed by more differentiated and less myelosuppressive disease upon relapse of acute myeloid leukemia. Blood 113: 1086-1096

101. Neubauer A, Maharry K, Mrozek K, Thiede C, Marcucci G, et al. (2008) Patients with acute myeloid leukemia and RAS mutations benefit most from postremission high-dose cytarabine: a Cancer and Leukemia Group B study. J Clin Oncol 26:4603-4609.

102. Schnittger S, Eder C, Jeromin S, Alpermann T, Fasan A, et al. (2013) ASXL1 exon 12 mutations are frequent in AML with intermediate risk karyotype and are independently associated with an adverse outcome. Leukemia 27: 82-91.

103. Chou WC, Huang HH, Hou HA, Chen CY, Tang JL, et al. (2010) Distinct clinical and biological features of de novo acute myeloid leukemia with additional sex comb-like 1 (ASXL1) mutations. Blood 116: 4086-4094.
104. Pratcorona M, Abbas S, Sanders MA, Koenders JE, Kavelaars FG, et al. (2012) Acquired mutations in ASXL1 in acute myeloid leukemia: prevalence and prognostic value. Haematologica 97: 388-392.

105. Janin M, Mylonas E, Saada V, Micol JB, Renneville A, et al. (2014) Serum 2-hydroxyglutarate production in IDH1- and IDH2-mutated de novo acute myeloid leukemia: a study by the Acute Leukemia French Association group. J Clin Oncol 32: 297-305.

106. Marcucci G, Maharry K, Wu YZ, Radmacher MD, Mrózek K, et al. (2010) IDH1 and IDH2 gene mutations identify novel molecular subsets within de novo cytogenetically normal acute myeloid leukemia: a Cancer and Leukemia Group B study. J Clin Oncol 28: 2348-2355.

107. Paschka P, Schlenk RF, Gaidzik VI, Habdank M, Krönke J, et al. (2010) IDH1 and IDH2 mutations are frequent genetic alterations in acute myeloid leukemia and confer adverse prognosis in cytogenetically normal acute myeloid leukemia with NPM1 mutation without FLT3 internal tandem duplication. J Clin Oncol 28: 3636-3643.

108. Green CL, Evans CM, Hills RK, Burnett AK, Linch DC, et al. (2010) The prognostic significance of IDH1 mutations in younger adult patients with acute myeloid leukemia is dependent on FLT3/ITD status. Blood 116: 2779-2782.

109. Weissmann S, Alpermann T, Grossmann V, Kowarsch A, Nadarajah N, et al. (2012) Landscape of TET2 mutations in acute myeloid leukemia. Leukemia 26: 934-942.

110. Gaidzik VI, Paschka P, Späth D, Habdank M, Köhne CH, et al. (2012) TET2 mutations in acute myeloid leukemia (AML): results from a comprehensive genetic and clinical analysis of the AML study group. J Clin Oncol 30: 1350-1357.

111. Ley TJ, Ding L, Walter MJ, McLellan MD, Lamprecht T, et al. (2010) DNMT3A mutations in acute myeloid leukemia. N Engl J Med 363: 2424-2433.

112. Gaidzik VI, Schlenk RF, Paschka P, Stölzle A, Späth D, et al. (2013) Clinical impact of DNMT3A mutations in younger adult patients with acute myeloid leukemia: results of the AML Study Group (AMLSG). Blood 121: 4769-4777.

113. Hou HA, Kuo YY, Liu CY, Chou WC, Lee MC, et al. (2012) DNMT3A mutations in acute myeloid leukemia: stability during disease evolution and clinical implications. Blood 119: 559-568.

114. Van Vlierberghe P, Palomero T, Khiabanian H, Van der Meulen J, Castillo M, et al. (2010) PHF6 mutations in T-cell acute lymphoblastic leukemia. Nat Genet 42: 338-342. 